\title{
DESIGN AND CONSTRUCTION OF SAVONIUS ROTOR
}

\section{Mirsad Hyder Shah}

Student, Technische Universitat Dortmund.

Dortmund, (Germany).

E-mail: Itsmirsadhyder@yahoo.com ORCID: https://orcid.org/0000-0003-2476-5887

Sameer Ali Alsibiani

MD. Yanbu University College, Yanbu Industrial City, (Kingdom of Saudi Arabia). E-mail: Alsibianis@rcyci.edu.sa ORCID: https://orcid.org/0000-0003-1918-5175

\section{Gitación sugerida Suggested citation}

Hyder, M., y Ali, S. (2020). Design and construction of Savonius rotor. 3C Tecnología. Glosas de innovación aplicadas a la pyme. Edición Especial, Noviembre 2020, 65-77. https://doi.org/10.17993/3ctecno.2020. specialissue6.65-77 


\section{ABSTRACT}

Renewable energy sources have been researched for more than a century now. Wind energy; which is often characterized as an unreliable source of energy, is not unreliable if placed at places with smooth wind currents. Savonius rotor as Vertical Axis Wind Turbine (VAWT) can be used as a standalone power generation device because of its low cost, low cut-in speed and the fact that it can accept wind from any direction. S-Rotors when compared to other types of rotors have a lower Power Coefficient but factors like Overlap ratio, Aspect Ratio, Number of Blades and Blade shapes can affect its efficiency. This paper discusses the Design and construction of a Savonius wind turbine by studying how the factors above influence the rotor's performance. Finally, a Single-stage, Two blade conventional Savonius rotor with an Overlap Ratio of 0.1 and Aspect Ratio of 3.3 has been constructed and discussed below. Studies for choosing the best material have also been conducted and PolyVinyl Chloride (PVC) has been selected to prepare the blades from. According to the study conducted, the voltage output recorded at $5.4 \mathrm{~m} / \mathrm{s}$ wind speed was 19.1 Volts.

\section{KEYWORDS}

Savonius Rotor, Wind Turbine, S-Rotor, HAWT, VAWT. 


\section{INTRODUCTION}

Wind turbines are classified into two categories: HAWT and VAWT. This classification refers to the position of rotor axis relative to wind direction. The Savonius rotor is thus used as vertical axis wind turbine like the other Darrieus rotor. S-Rotors or Savonius rotors have been employed as VAWT widely in the previous decades. The main reasons for which S- rotors are employed in residential areas are because they are self-starting, produce low noise and can accept wind energy from any directions. S-Rotors are also employed at places with low wind potential and where HAWTs cannot run. Since the $\mathrm{C}_{\mathrm{p}}$ (Power Coefficient) of an S-Rotor is poor in large wind turbines, design parameters are altered as to improve the power coefficient by reducing the size of the rotor itself (Al-Kayiem, Bhayo, \& Assadi, 2016).

The S-rotor was invented by Finnish engineer S. J. Savonius in 1925. As discussed earlier, S-Rotors are generally preferred over D-rotor because of low cut-in speeds and high torque, but their $\mathrm{C}_{\mathrm{p}}$ is poor when compared with other wind turbines. In 1919, German physicist Albert Betz put forth what is known as the Betz theory. According to him, the theoretical maximum efficiency for a wind turbine is $59.3 \%$. This value is generally known as the Betz limit for wind turbines (Al-Kayiem et al., 2016).

Because of their superiority over other wind turbines, S-Rotors have been used to harness energy for various purposes; mainly power generation, to meet electricity demands (AlKayiem et al., 2016).

\section{RESEARCH DESIGN AND CONSTRUCTION}

\subsection{BLADES SHAFT AND COUPLING OF WIND TURBINE}

For the design of blades and the selection of material for the wind turbine, following factors were taken into consideration:

- The blades of the windmill should not break if winds with high current cross the surface.

- The material should not decompose over time and not prone to rusting in harsh environment. 
- The material should be easily accessible.

- The cost of the material should be low cost.

- The blades should be durable in the long run.

Considering all the reasons mentioned above, Polyvinyl Chloride (PVC) was the best choice available. After cutting the PVC to achieve the desired design the edges were smoothened with sandpaper.

Table 1. Parameters and Values of Blades Shaft and Coupling.

\begin{tabular}{|c|c|}
\hline PARAMETERS & VALUES \\
\hline Diameter of turbine & $0.375 \mathrm{~m}$ \\
\hline Volume of Blade & $0.0395 \mathrm{~m}^{3}$ \\
\hline Diameter of Single Blade & $0.203 \mathrm{~m}$ \\
\hline Overlap distance & $0.0381 \mathrm{~m}$ \\
\hline Density of PVC & $1467 \mathrm{~kg} / \mathrm{m}^{3}$ \\
\hline Mass of PVC & $3.8 \mathrm{~kg}$ \\
\hline Blade angle & $180^{\circ}$ \\
\hline Shaft Height & $1.34 \mathrm{~m}$ \\
\hline Shaft Diameter & $0.036 \mathrm{~m}$ \\
\hline Coupling Height & $0.058 \mathrm{~m}$ \\
\hline Bush size & $0.02 \mathrm{~m}$ \\
\hline
\end{tabular}

The blades were weld to a shaft at an angle of 90 degrees, this enabled the blades to be rotated by wind currents. The shaft had to be strong enough to withstand strong gushes of wind and considering the work of Menet (2004); the shaft was made out of PVC.
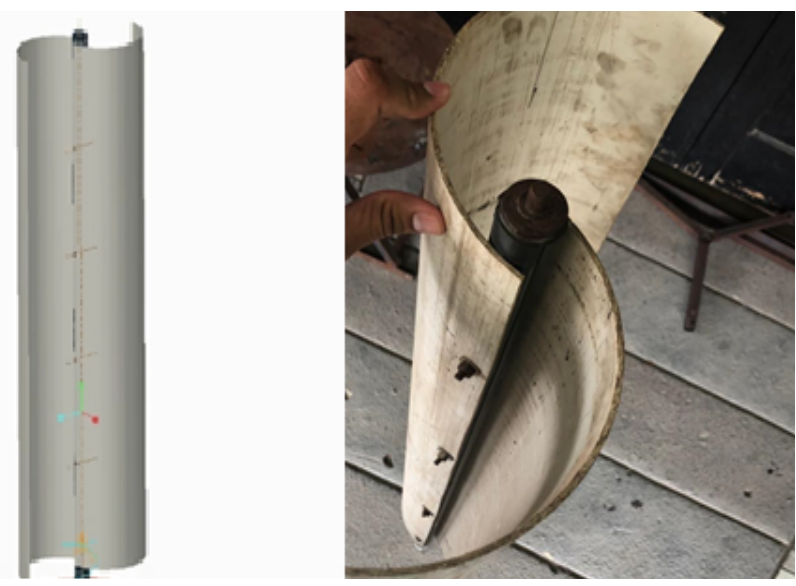

Figure 1. AutoCAD vs Hardware of Blades and Shaft. 


\subsection{BASE OF WIND TURBINE}

For the construction of the base, mild steel bars were welded together to provide stability to the whole design. For maximum stability a four legged stand base was proposed and implemented.

Table 2. Parameters and values of base height and diameter.

\begin{tabular}{|c|c|}
\hline PARAMETERS & VALUES \\
\hline Base Height & $0.36 \mathrm{~m}$ \\
\hline Base Diameter & $0.56 \mathrm{~m}$ \\
\hline
\end{tabular}
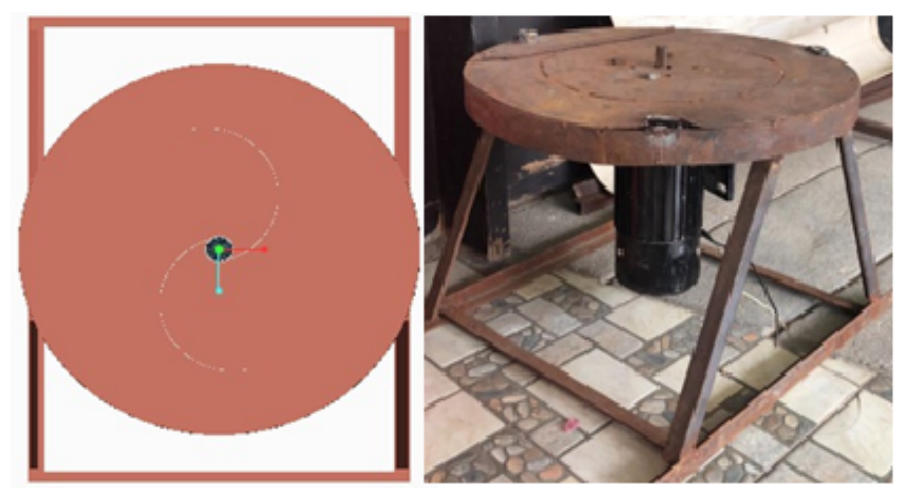

Figure 2. AutoCAD vs Hardware of Base of Turbine.

\section{IMPORTANT DESIGN PARAMETERS OF SAVNOIUS ROTORS}

- Overlap Ratio.

- Aspect Ratio.

- Number of Blades.

- Number of Stages.

- Blade Shapes.

\subsection{OVERLAP RATIO}

The overlap ratio is ratio of the overlap distance (the distance by which the inner edge of the blade overlaps the inner edge of the adjacent blade) by the diameter of the entire turbine. As shown below in figure (Al-Kayiem et al., 2016). 


$$
\text { Overlap Ratio }=\beta=\frac{e}{D}
$$

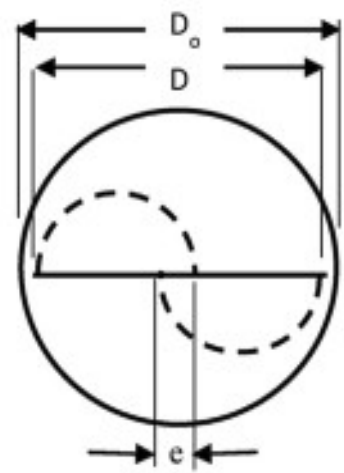

Figure 3. S-Rotor with Overlap ratio. Source: (Al-Kayiem et al., 2016).

\subsection{ASPECT RATIO}

Aspect Ratio is the ratio of Rotor's height $\mathrm{H}$ to its Diameter D;

$$
\text { Aspect Ratio }=\frac{H}{D}
$$

Increasing Aspect ratio increases performance and angular speed of the rotor. Aspect ratio is adjusted to meet the torque and RPM requirements of the generator, which will produce electricity (Al-Kayiem et al., 2016).

Blackwell, Sheldahl, and Feltz (1978), experimentally concluded that increasing aspect ratio increased the power coefficient (while keeping all other parameters constant).

\subsection{NUMBER OF BLADES}

With an increase in the number of blades the power coefficient decreases. This decrease is due to the fact that, as the number of blades is increased, more wind is deflected by a blade from entering into the concave side of its adjacent blades (Al-Kayiem et al., 2016).

Al-Kayiem et al. (2016) in his work concluded that S-Rotors indeed do perform better at low wind currents. It is also compared and concluded that two blades perform better than 
three blades as more drag is wasted in the three-blade system. The $\mathrm{G}_{\mathrm{p}}$ of two blade design is much better than a three-blade system.

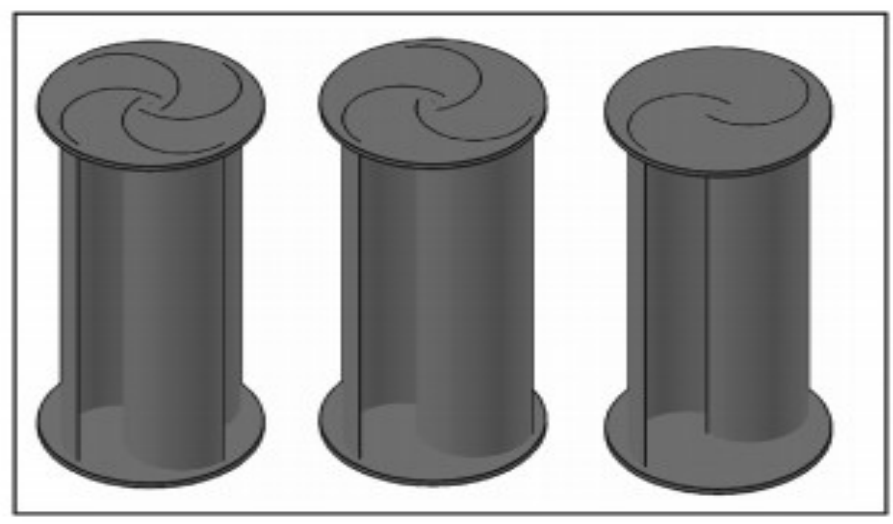

Figure 4. S-Rotor with various number of blades. Source: (Al-Kayiem et al., 2016)

\subsection{NUMBER OF STAGES}

Number of stages mean one or more stages of an S-Rotor in a single design. This means that the wind currents will have more area to sweep through and better torque uniformity around 360 degrees. This eliminates the dead zones left by rotor's blades that are not rotating. Note that the stages of an S-Rotor are shifted at a specific phase shift angle.

In his paper, Al-Kayiem et al. (2016), debated that a Double staged S-Rotor may produce the best power coefficient as compared to a single or three staged S-Rotor. This explains the hypothesis that as the stages of an S-Rotor are increased it means if one of the stages of S-Rotor is rotating it must carry the inertia of the other stages since they are not producing any torque.

Saha, Thotla, and Maity (2008), in his experimental work, concluded that a single staged rotor gave $\mathrm{a}_{\mathrm{p}}$ of 0.18 , a two-staged rotor gave a power coefficient of 0.29 , while the threestaged demonstrated a $\mathrm{C}_{\mathrm{p}}$ of only 0.23 . 


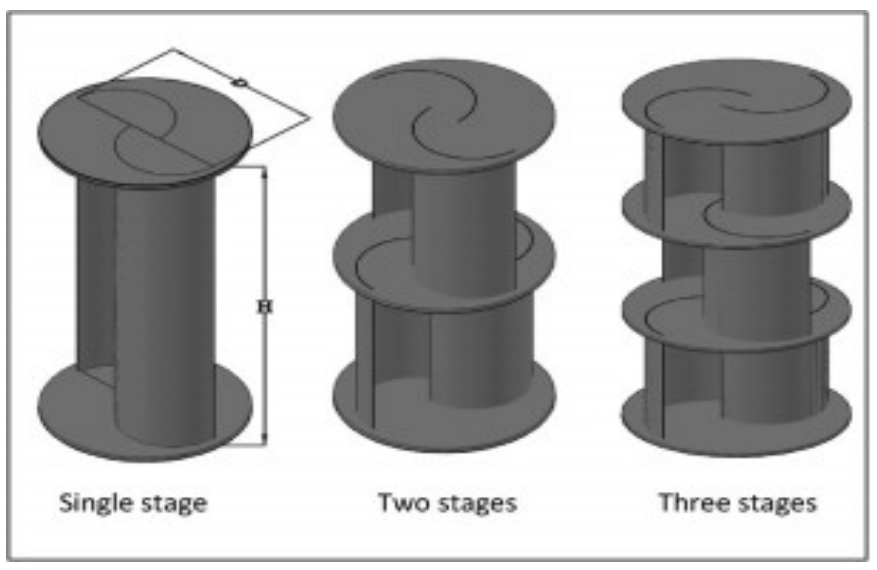

Figure 5. Single and Multistage S-rotors. Source: (Al-Kayiem et al., 2016).

\subsection{BLADE SHAPES}

Although S-Rotors are generally similar S-shaped rotors, there have been few attempts to modify the blade shape in order to increase its aerodynamic property in order to increase the $\mathrm{C}_{\mathrm{p}}$.

Muscoloa and Molfinob (2014) simulated five different S-type VAWTs, including a simple S-Roto. In the four wind rotors, two were new models and two were proposed by Kyozuka (2008). The rotor named Bronzinus, performed the best and produced the highest power coefficient. But if the tip speed was crossed $\mathrm{C}_{\mathrm{p}}$ of the wind rotor proposed by Menet (2004) was found to be superior.

\section{FINAL DESIGN OF ROTOR AND ASSEMBLY}

The Rotor assembly consisted of the following parts:

- Base:

The base was made up of mild steel. The purpose of the base was to hold the rotor in its place and provide a suitable height above the ground for the blades to face the wind. The PMDC motor was coupled under the base as well. To provide maximum strength Mild steel bars were welded in an L-shaped arrangement. 
- Bearing \& Bearing Housing:

The purpose of the bearing was to support the shaft and lessen the friction for the shaft to rotate. The bearing housing protects the bearing from any damage and restricts the movement of the shaft.

\section{- Motor Housing:}

Motor housing consists of two horizontal plates made of Mild Steel which will have the motor sandwiched in the between. The top end of the motor was secured to the assembly by screws.

\section{- Rotor Shaft:}

The rotor shaft was made up of PVG. Due to its high strength, Polyvinyl Chloride was chosen to withstand bending forces exerted by the rotating blades. The shaft had to be strong enough to withstand strong gushes of wind and considering the work of Menet (2004); the shaft was made out of PVG.

\section{RESULTS}

The parameters and values for the final design have been presented in Table 3 . As the factors discussed above have been carefully considered such that the power coefficient of the rotor never drops. According to Al-Kayiem et al. (2016), the average Power Coefficient of an S-rotors under open flow conditions ranges from 0.037 to 0.37 . However, the Power Coefficient of S-rotors with external flow guides can reach up to 0.52 .

Table 3. Parameters and values of Final Design.

\begin{tabular}{|c|c|}
\hline PARAMETERS & VALUES \\
\hline Model type & Two blade conventional Savonius rotor \\
\hline Height & $1.25 \mathrm{~m}$ \\
\hline Diameter & $0.375 \mathrm{~m}$ \\
\hline Area & $0.456 \mathrm{~m}^{2}$ \\
\hline Aspect ratio & 3.3 \\
\hline Overlap ratio & 0.1 \\
\hline Number of stages & 1 \\
\hline Number of Blades & 2 \\
\hline Design of Blade & Conventional Blade \\
\hline
\end{tabular}


In the Figure 6, the AutoCAD drawing and the actual hardware are shown. As the Savonius rotor has a conventional blade design and it is a two blade system. Furthermore, it uses minimal area and takes only $0.456 \mathrm{~m}^{2}$ of area. The factors affecting the power coefficient of the S-rotor have also been calculated and presented.
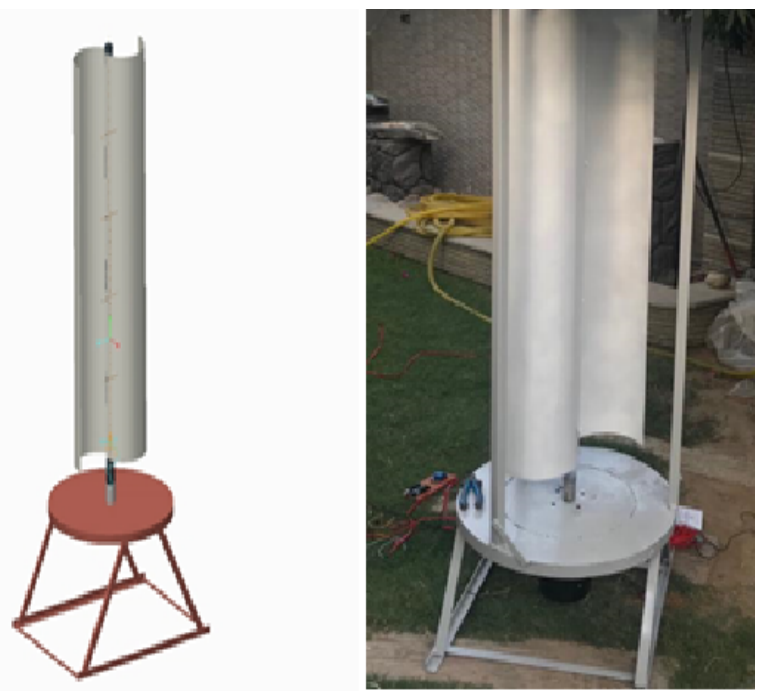

Figure 6. AutoCAD vs Hardware of S-rotor.

In Table 4, the results for the wind turbine have been shown. The velocity of the wind was measured using an anemometer which was placed right in front of the rotor. The wind made the rotor move as intended. However, the maximum wind velocity that could be simulated was $5.4 \mathrm{~m} / \mathrm{s}$. On the Beaufort Scale, such a wind speed has a Beaufort number of 3 and is considered as a Gentle Breeze only. But due to the rotor being lightweight it was easily rotated, and enough Revolutions were generated. At a windspeed of $5.4 \mathrm{~m} / \mathrm{s}$, the generator under the S-Rotor generated 19.1 Volts.

Table 4. Results of Wind Turbine.

\begin{tabular}{|c|c|c|}
\hline WIND SPEED m/s & RPM & VOLTAGES \\
\hline 4.1 & 200 & $14.91 \mathrm{~V}$ \\
\hline 4.5 & 241 & $17.0 \mathrm{~V}$ \\
\hline 4.9 & 253 & $18.17 \mathrm{~V}$ \\
\hline 5.1 & 265 & $18.64 \mathrm{~V}$ \\
\hline 5.4 & 302 & $19.1 \mathrm{~V}$ \\
\hline
\end{tabular}




\section{CONCLUSION}

This paper presented a study in which S-rotors have been employed as a power generation unit. The design and construction of a Savonius rotor has been carried out in this paper and S-rotors have been proved to be used in power generation units. S-Rotors are generally highly affected by varying geometric parameters and blade shapes. S-rotors produce high starting torques and low cut-in speeds. Furthermore, factors such as Overlap Ratio, Aspect ratio, number of blades and number of stages have been briefly discussed in this paper. It is also concluded that by increasing/decreasing the factors discussed above, the Power Coefficient of the wind turbine varies. For the design of blades and the selection of material for the wind turbine, Poly Vinyl Chloride (PVC) was chosen as the best material available. It was chosen mainly because of its low cost and durability. Furthermore, choosing the suitable Aspect and Overlap ratio is a difficult task but from the work of Blackwell et al. (1978) it can be inferred that keeping the Overlap ratio to a minimal and increasing the Overlap ratio; increased the power coefficient of the Savonius Rotor. Finally, for a better power coefficient, the authors predict a two blade two stage rotor will do a better job for conventional wind turbines but will prove ineffective if the wind currents are equally distributed from the top to the bottom on the whole blade design.

\section{REFERENCES}

Al-Kayiem, H. H., Bhayo, B. A., \& Assadi, M. (2016). Comparative critique on the design parameters and their effect on the performance of S-rotors. Renewable Energy, 99, 1306-1317. https://doi.org/10.1016/j.renene.2016.07.015

Blackwell, B. F., Sheldahl, R. E., \& Feltz, L. V. (1978). Wind tunnel performance data for two-and three-bucket Savonius rotors. Fournal of Energy, 2(3), 160-164. https:// pdfs.semanticscholar.org/9c43/b666ff48d4396dc6a42cb27eb9f6a6563c21.pdf

Kyozuka, Y. (2008). An experimental study on the Darrieus-Savonius turbine for the tidal current power generation. Fournal of Fluid Science and Technology, 3(3), 439-449. https://doi.org/10.1299/jfst.3.439 
Menet, J. L. (2004). A double-step Savonius rotor for local production of electricity: a design study. Renewable energy, 29(11), 1843-1862. https://doi.org/10.1016/j. renene.2004.02.011

Muscoloa, G. G., \& Molfinob, R. (2014). From Savonius to Bronzinus: a comparison among vertical wind turbines. Energy Procedia, 50, 10-18. https://doi.org/10.1016/j. egypro.2014.06.002

Saha, U. K., Thotla, S., \& Maity, D. (2008). Optimum design configuration of Savonius rotor through wind tunnel experiments. Fournal of Wind Engineering and Industrial Aerodynamics, 96(8-9), 1359-1375. https://doi.org/10.1016/j.jweia.2008.03.005 
3C Tecnología. Glosas de innovación aplicadas a la pyme. ISSN: 2254 - 4143 Edición Especial Special Issue Noviembre 2020 